\title{
Study of Impact of Socio-Economic Condition of Patients on Rhinosporidiosis in a Tertiary Level Hospital of Bangladesh
}

Abdul Qayum Chowdhury ${ }^{* *}$

Department of Otolaryngology and Head-Neck Surgen Chattagram Maa-O-Shishu Hospital Medical College Chittagong, Bangladesh.

${ }^{*}$ Correspondence to:

\section{Dr. Abdul Qayum Chowdhury}

Associate Professor

Department of Otolaryngology and Head-Neck Surgery Chattagram Maa-O-Shishu Hospital Medical College Chittagong, Bangladesh.

Mobile: +88 01711120017

Email: qayumchowdhury@yahoo.com

www.banglajol.info/index.php/CMOSHMCJ

\begin{abstract}
Background: Rhinosporidiosis has been known for over a hundred years since its first description in Argentina. It is a chronic granulomatous,non contagious infective condition characterized by a production of nasal polyps and other manifestation of nasal hyperplasia, with frequent recurrence after surgery. The objective of this present study was Impact of Socio-economic condition of patients on Rhinosporidiosis. Methods: 34 number of patients were included in this study with symptomatic Rhinosporidiosis. The main outcome of study were age, sex, socioeconomic status, Occupation, bathing habit and living area of patients. Results: The study showed that 61.76 percent of patients were in the age group of 6-20 years. The mean age of 20.62 ( $\mathrm{SD} \pm 13.87$ ) years. Most of the Rhinospridiosis patiets were from lower economic class $24(70.59 \%)$ followed by middle class $9(26.47 \%)$ and $1(2.94 \%)$ patients were upper class of socioeconomic status.Student was the most common occupation of Rhinosporidiosis 17(50\%) followed by farmer $7(20.59 \%)$. Most of the Rhinosporidiosis patients 31(91.18\%) were taking bath in pond where cattle also take bath. Conclusion: Rhinosporidiosis are very common in male and frequent age incidence are 6-20 years. Most of the Rhinospridiosis patient were from lower economic class and most of the Rhinosporidiosis patient were taking bath in pond where cattle also take bath.
\end{abstract}

Key words: Rhinosporidiosis; Socio-economic status; Nasal hyperplasial.

\section{INTRODUCTION}

Rhinosporidiosis has been known for over a hundred years since its first description in argentina ${ }^{1}$. Guillermo Seeber described the first case of rhinosporidiosis in Buenos Aires in $1900^{1}$. It is a chronic granulamatous,non contagious infective condition characterized by production of nasal polyps and other manifestation of nasal hyperplasia, with frequent recurrence after surgery. The disease is endemic in Sir Lanka and India (Karunaratne,1964). Reports of sporadic cases have been issued from Argentina, Brazil, Iran,the United States,South Africa,Central and East Africa and South Asia. It is endemic at Raipur in India ${ }^{2}$. Outbreaks of human and animal disease have been recently described in Europe and reports of sporadical cases in temperate and tropical countries continue to appear ${ }^{3}$. Increased migration of persons who acquired Rhinosporidiosis in their native Asian countries has resulted in the increasing incidence of this disease in non-endemic areas. Rhinosporidiosis is an infective disease as tissue lesions are always associated with the presence of the pathogen (Sporangia) ${ }^{4}$. No evidence has ever been documented of cross-infection between members of the same family or between animals and humans. The great majority of cases are sporadic, but predisposing factors in the host may be a cause of its endemicity. 
The probable mode of infection from the natural aquatic habitat of Rhinosporidium seeberi is through traumatized epithelium,most commonly in the nasal cavity. Autoinoculation is known to cause satellite lesions adjacent to granulomas especially in the upper respiratory sites. Spillage of endospores from polyps after trauma or surgery is thought to be followed by autoinoculation through the adjacent epithelium. There is evidence for hematogenous spread of rhinosporidiosis to anatomically distant sites, as evidenced by the development of subcutaneous granuloma in the limbs without breach of the overlying skin ${ }^{6}$. The mode of regional spread, however,is controversial. Ashworth suggested the possibility of lymphatic spread $^{7}$.

Characteristically, rhinosporidial lesions in the nasal cavity are polypoidal,granular,and red in colour due to pronounced vascularity. The surface contains yellowish pinhead-sized spots representing underlying mature sporangia. A covering of mucoid secretions is not uncommon.Nasopharyngeal lesion are often multi-lobed with variegated appearance,typical strawberry like lesions and areas that have relatively less vascular lobes with smooth surfaces.

A majority of cases occur in upper respiratory sites, notably the anterior nasal cavity, the inferior turbinate, septum and floor. Rhinosporidial lesions also occur in the soft palate, nasopharynx and larynx, and rarely the buccal mucosa. The disease, while being of special interest to an otorhinolaryngologist, is of interest to dermatologists and ophthalmologists as well, through the occurrence of granulomas in the skin, subcutaneous tissues and eyes. About $2 \%$ of cases of rhinosporidiosis affect the bulbar and palpebral conjunctiva. Rhinosporidiosis of the lacrimal sac and nasolacrimal duct has also been documented ${ }^{8}$.

The definitive diagnosis of rhinosporidiosis is by histopathology, with the identification of the pathogen in its diverse stages.Although all the developmental stages of the pathogen has definitive characterstics which allow histopathological diagnosis, some notable features include the wide variation within a single specimen, in lesions of different sites, in respect to both endospores and sporangia, as well as the cellular response of the host.

The etiologic agent Rhinosporidium seeberi, initially described as a protozoan by Seeberi, started to be a classified as a fungus by Ashworth. However, several enigmas still persist even today regarding R. seeberi, due to the failure of attempts at sustained in vitro culture, and the failure to establish rhinospordiosis in experimental animals. Though molecular biological analysis of the organisms ribosomal DNA suggests it to be a cyanobacterium, like Microcystitis aeruginosa, some considers it a mesomycetozoan 9 .
Several trials have shown that the most successful treatment, with the lowest incidence of recurrence, is wide base surgical excision and cauterization of the base of the lesions. Unfortunately,reports regarding recurrence rates are very few. Satyanarayana et al.reported a recurrence rates of $11 \%$ after surgical treatment, Khan et al.followed with 22 patients of whom 18 were treated by cutting diathermy.

The latter patients had no recurrences, whereas of the four cases in which the lesions were removed with forceps and snares, all had recurrent disease. Conservative treatment as a single modality is not widely used,but in one clinical trial by Nair et al.in 1979 applying diaminophenylsulfone to 32 patients with nasoparyngeal rhinosporidiosis, $71.4 \%$ patients did not show recurrence in a three year period and none of them needed additional surgery during that period.

\section{AIMS OF STUDY}

The aims of the study are:

To observe the impact of Socio-economic condition of patient on Rhinosporidiosis on the basis of Age, Sex, Socio-economic status, Occupation, bathing habit and Living area.

\section{MATERIAL AND METHODS}

This presented study was prospective cross sectional study in the Department of Otolaryngology and Head-Neck Surgery of Chattagram Maa Shishu-O-General Hospital (CMSOGH) of Chittagong, during the period from June 2012 to May 2014 with a view to find out the impact of Socioeconomic condition of patients on Rhinosporidiosis. Altogether 34 conveniently selected cases of Rhinosporidiosis of Nasal cavity of different age and sex group had been studied. Different parts of nasal cavities were included in the study. Other regions except nasal cavity were excluded from the study. Data were collected in a predesigned form. No data or information was collected without permission of patients, participation of this study is fully voluntary. Data were analyzed by using computer based Statistical Package of Social Science (SPSS, Version 20) programme. Categorical variables was presented in the form of frequency and percentage. Quantitative data were presented in the form of mean and standard deviation.

\section{RESULTS}

The outcome of the study was as follows:

\section{Distribution of the patients according to different age and} sex of patients:

Table 1, showed the distribution of patients according to different age and sex of patients. There were 21(61.76\%) patients were in the age group of 6-20 years, $7(20.59 \%)$ patients in the age group of $21-35$ years, $5(14.71 \%)$ patients were in the age group of $36-50$ years and $1(2.94 \%)$ patients were in the age group of above 50 years. There were $24(70.59 \%)$ male and $10(29.41 \%)$ female with a ratio of male to female was $2.4: 1$.Here in case of age $p$ value is $<0.05$. So it can be said that Rhinosporidiosis is common in 6-20 years of age. In case of sex $\mathrm{p}$ value is $<0.05$. So Rhinosporidiosis is more common in male than female. 
Table 1: Distribution of the patients according to different age and $\operatorname{sex}(\mathrm{n}=34)$.

$\begin{array}{lrrrr}\text { Age group } & \text { Male \% } & \text { Female \% } & \text { Total (\%) } & \text { p value } \\ 6-20 & 15(44.12 \%) & 6(17.64 \%) & 21(61.76 \%) & \\ 21-35 & 5(14.71 \%) & 2(5.88 \%) & 7(20.59 \%) & \\ 36-50 & 4(11.77 \%) & 1(2.94 \%) & 5(14.71 \%) & <0.05 \\ >50 & 0(\%) & 1(2.94 \%) & 1(2.94 \%) & \\ \text { Grand total } & 24(70.60 \%) & 10(29.40 \%) & 34(100 \%) & \end{array}$

Mean and standard deviation of age distribution of the patients

Table 2, the age of the patients ranged from 6 to 60 years with the mean age of $20.62(\mathrm{SD} \pm 13.87)$ years. The age of the male patients ranged from 6 to 40 years with the mean age of 17.87 $(\mathrm{SD} \pm 11.25)$ years, while the age of the female patients ranged from 7 to 60 years with the mean age of $27.2(\mathrm{SD} \pm 17.97)$ years. Here $p$ value is $<0.05$. So the mean age of the female patients was significantly higher than that of male patients.

Table 2 : Mean and standard deviation of age distribution of the patients.

\begin{tabular}{lcccc} 
Study Group & \multicolumn{3}{c}{ Age in Years } & \\
& Range & Mean & Standard deviation & p value \\
Total (n=34) & $6-60$ & 20.62 & 13.87 & \\
Male (n=24) & $6-40$ & 17.87 & 11.25 & $<0.05$ \\
Female (n=10) & $7-60$ & 27.2 & 17.97 & \\
\hline
\end{tabular}

\section{Distribution of socioeconomic status of the patients}

Figure 1, showed the distribution of socioeconomic status of the patients. Most of the Rhinosporidiosis patients were from lower economic class $24(70.59 \%)$, followed by middle class $9(26.47 \%)$ and $1(2.94 \%)$ patients were from upper class of socioeconomic status. Here $\mathrm{p}$ value is $<0.05$. So it is significantly common in low socio-economic people.

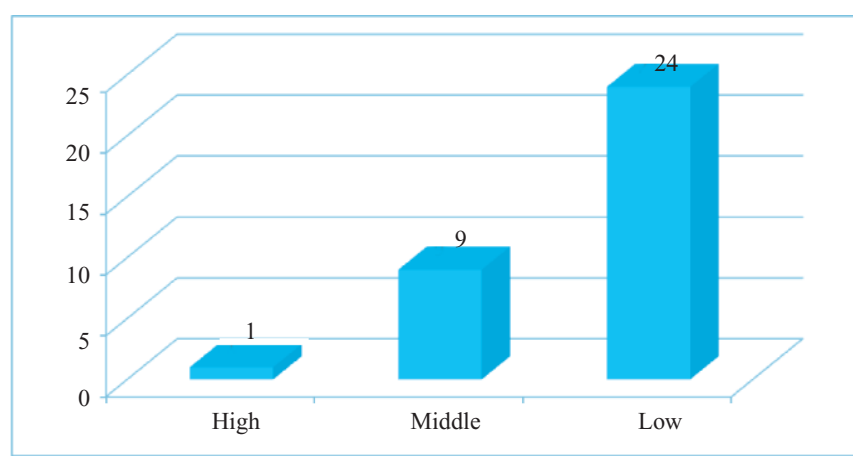

Figure 1: Distribution of socioeconomic status of the patients $(n=34)$.

\section{Distribution of patients according to occupation}

Table 3, showed the distribution of patients according to occupation. Student was the most common occupation of Rhinosporidiosis $17(50 \%)$, followed by farmer $7(20.59 \%)$ housewife $5(14.71 \%)$ businessmen $2(5.88 \%)$ day labourer $2(5.88 \%)$ others $1(2.94 \%)$.
Table 3 : Distribution of patients according to occupation $(n=34)$.

\begin{tabular}{lrcr} 
Occupation & Frequency & Percentage & p value \\
Student & 17 & $50 \%$ & \\
Housewives & 5 & $14.71 \%$ & \\
Day labourer & 2 & $5.88 \%$ & \\
Businessmen & 2 & $5.88 \%$ & $<0.05$ \\
Farmer & 7 & $20.59 \%$ & \\
Others & 1 & $2.94 \%$ & \\
Total & 34 & $100 \%$ & \\
\hline
\end{tabular}

Distribution of patients according to their living area

Figure 2, showed the distribution of patients according to their living area. Most of the Rhinosporidiosis patients $23(67.65 \%)$ were from rural and $11(32.35 \%)$ patients were urban by area of living. Here $p$ value is $<0.05$. So it is more common in rural people.

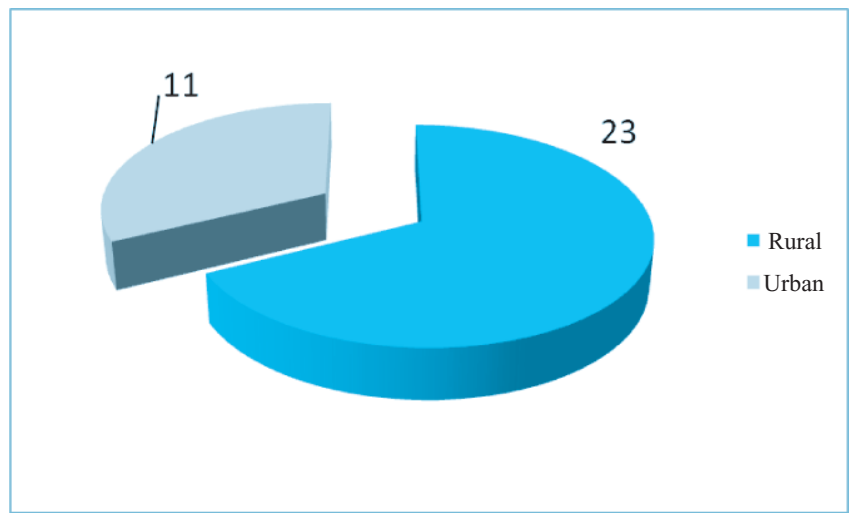

Figure 2 : Distribution of patients according to their living area $(n=34)$.

\section{Distribution of patients according to their bathing habit in pond}

Figure 3, showed the distribution of patients according to their bathing habit in pond. Most of the Rhinosporidiosis patients $31(91.18 \%)$ were taking bath in pond where cattle also take bath and $3(8.82 \%)$ patients were not do it.

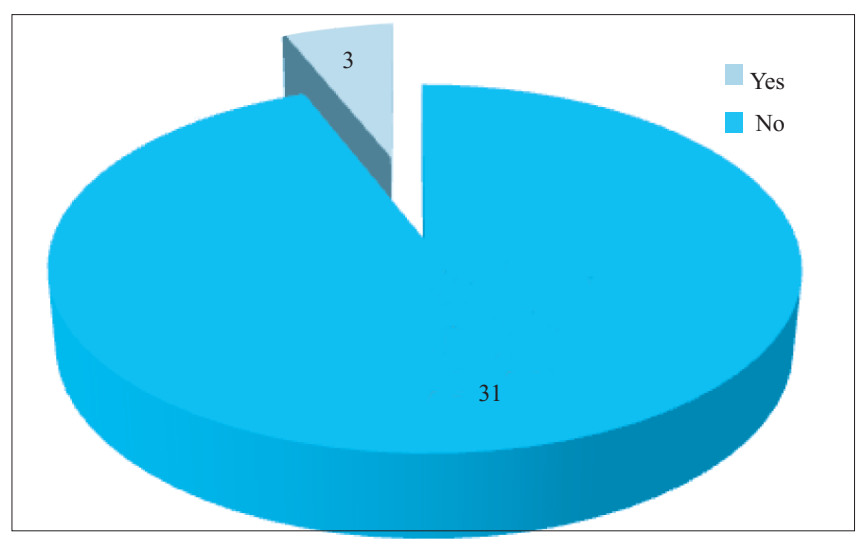

Figure 3 : Distribution of patients according to their bathing habit in pond $(n=34)$. 


\section{DISCUSSION}

To find out if Rhinosporidiosis is closely related with occupation, social status, personal habit and area of living of an individual. This observational study was conducted in the Department of Otolaryngology and Head-Neck Surgery, Chattagram Maa Shishu-O-General Hospital (CMSOGH) Bangladesh, during the period from June 2012 to May 2014 . For this purpose 34 (Thirty four) patients were selected whit rhinosporidiosis who fulfilling the inclusion and exclusion criteria. The outcome of the study was as follows:

The present study also showed that there were $21(61.76 \%)$ patients in the age group of 6-20 years, $7(20.59 \%)$ patients in the age group of $21-35$ years, $5(14.71 \%)$ patients in the age group of $36-50$ years and $1(2.94 \%)$ paitents in the age group of 51-65 years. This result was similar to a study carried out in india by Dr.R.Usha Kim, Dr.Prateek Agarwal, Dr.Hadi M Khazei, among 50 patients $36 \%$ were in the age group of $11-20$ yeares ${ }^{10}$. It was also similar with another study carried out in Department of Pathology, S. N. Medical Collage, Bagalkot587102. Karnataka, india where among 12 patients 5 (41.6\%) were in the age group of $11-20^{11}$. Another study shows same similarity with this ${ }^{12}$

The current study showed that there were $24(70.59 \%)$ male and $10(29.41 \%)$ female with a ratio of male to female was $2.4: 1$. From this data we can say that rhinosporidiosis is common in male than female. Similar finding( the male female ratio is 2.3:1) were reported in the study carried out in Department of Microbiology, Faculty of Medicine, University of Peradeniya, Srilanka ${ }^{13}$.

In this stydy the age of the patients ranged from 6 to60 years with the mean age of 20.62 ( $\mathrm{SD} \pm 13.87$ ) years. The age of the male patients ranged from 6 to 40 years with the mean age of 17.87( $\mathrm{SD} \pm 11.25)$ years, while the age of the female patients ranged from 7 to 60 years with the mean age of 27.2 $(\mathrm{SD} \pm 17.97)$ years. In one study that was carried in department of Otorhinolaryngology and Head-Neck surgery, S Nijlaingappa Medical College and HSK Hospital and RC between 2005 to 2009 on 17 patients the mean age is 28.4 years $^{14}$.

The current study showed that most of the rhinosporidiosis patients were from lower economic class 24 (70.59\%). Followed by middle class $9(26.47 \%)$ and upper class 1 $(2.94 \%)$.From these finding it can be said that rhinosporidiosis is common in low socioeconomic people. It was similar with a study carried in B P Koirala Institute of Medical Sciences, Dharan, Nepal ${ }^{15}$. The population of low economic status are more frequently attacked, with the majority of patients coming from agricultural zone an those taking bath in ponds ${ }^{15}$.
Regarding occupation this study showed that student was the most common occupation of rhinosporidiosis $17(50.0 \%)$, followed by farmer 7 (20.59\%) house wife 5 (14.71\%) businessman $2(5.88 \%)$ day labourer $2(5.88 \%)$ and others $1(2.94 \%)$. As most of the patients are between the age of 6-20 years so it is obvious that the most common occupation will be student. The populations of low economic status are more frequently attacked, with the majority of patients coming from agricultural zone and those taking bath in ponds ${ }^{15}$. Males engaged in agriculture tend to bath in nearby ponds after their work. These very ponds shared by cattle also ${ }^{16}$.

The present study showed that most of the rhinosporidiosis patients $21(67.65 \%)$ were from rural and 11 (32.35\%) patients were urban by social background. These findings were in accordance with the findings of in Nepal which shows that rhinosporidiosis is common in the Indo-Aryan race, this predominance is due to the population of this race in the eastern agricultural zone of $\mathrm{Nepal}^{15}$. As about $60 \%$ of our people living in rural area and ponds and river are situated mainly in rural area so it is obvious that the disease was common in rural people.

The current study showed that most of the rhinosporidiosis patients 31 (91.18\%) had positive bathing habit that means they are using such pond or river water which also used by cattle. It was similar with one study that was carried by in B P Koriala Institute of Medical Sciences, Dharan, Nepal where in 84 patients all of them have giving history of bathing pond or river water ${ }^{5}$. Some other studies have similarity with this study ${ }^{13}$.

\section{CONCLUSION}

Though a limited number of cases (34) included in the study, yet on the basis of this study it can be concluded that Rhinosporidiosis are more frequently attacked the population of low socioeconomic status with the majority of patients coming from agricultarul zone on those taking bath in ponds where cattle also take bath and are very common in male and frequently age incidence are 6-20 years and student was the most common occupation.

\section{DISCLOSURE}

The author declared no competing interest. 


\section{REFERENCES}

1. Lakshmanan M, Kameswaran S, Jayapal JI: Histochemistry of Rhinosporidium Seeberi. Proceedings of the international Symposium of Taxonomy of Fungi. Chennai, india. 1973.

2. Sudarsan V, Goel N K, Gahine R, Krishnani C, Rhinosporidiosis in Raipur, Chhattisgrah. A report of 462 cases. India journal pathol Microbiol. 2007; (50): 718-721.

3. Vukovic A, Bobic-Radovanovic A, Latkovic Z, Raduvanovic Z. An epidemiological investigation of the first outbreak of rhinosporidiosis in Europe. J Trop Med Hygiene. 1995;98:333-357.

4. Jain S. Aetiology and Incidence of Rhinosporidiosis. Indian Journal of Otorhinology. 1967;XIX(1):1-21.

5. Bhandary S, Natesh V, Tchettri S, Kumar A. Rhinosporidiosis: Analysis of cases presenting to a tertiary care hospital in Nepal. The internet journal of tropical Medicine. 2012; (8): 17-25.

6. Karunaratne WAE. The pathology of rhinosporidiosis . J Path Bact. 1934; XLII: 193-202.

7. Karunaratne WAE. Rhinosporidiosis in Man. The Athlone Press, London. 1964.

8. Rajam RV, Viswanathan GC. Rhinosporidiosis: A study with a report of a fatal case with systemic dissemination. Ind J Surg. 1955; 17:269-298.

9. Ashworth JH. On Rhinosopridiosis seeberi, with special reference to its sporulation and affinities. Trans Roy Soc, Edin; 1923; 53:301342.Kim RU, Agarwal P, Khazei HM. Ocular and Adexal Rhinosporiodiosis: A Prospective Study. AIOC 2009;402-403.

10. Sidhalingareddy,Khageshan AP,Miskin AT, Domble VD, Patil J. Rhinosporiodiosis: A stydy of 12 cases with etiological review Med Inn. $2013 ; 2: 77-80$

11. Toriyamai K, Uzata F AND Kamidigo NO. Rhinosporiodiosis in western Kenya Japan. J. Trop. Med. Hy. 1985;13(4):269-277.

12. Arseculeratne SN, Sumathiapala S and Eriyagama NB. Patterns of Rhinosporiodiosis in Srilanka: Comparison with international data southeast asian $\mathrm{j}$ trop med public health. 2010;42(1):175-191.

13. Chandrashekharayya SH, Suligavi SS, Chouggule S, Doddamani SS. Clinical Rhinology: An international Journal. 2010; (2) :73-75.

14. Bhandary S, Natesh V,Chettry ST, Kumar A.Rhinosporiodiosis: Analysis of cases Presenting To A.

15. Tertiary care Hospital in Nepal. The Internal journal of Tropical Medicine. 2012; 8 (1) DOI: 10.5580/2b70

16. Balasubramanian T, Geeta ST. Rhinosporiodiosis our experience. Journal of otolaryngology. 2011;1(1):2250-2359. 